\title{
1 An investigation of PS-b-PEO polymersomes for the oral treatment and diagnosis of 2 hyperammonemia
}

3 Simon Matoori ${ }^{1 *}$, Yinyin Bao ${ }^{1}$, Aaron Schmidt ${ }^{1}$, Eric J. Fischer ${ }^{2}$, Rafael Ochoa-Sanchez ${ }^{3}$, Mélanie

4 Tremblay $^{3}$, Mariana Oliveira ${ }^{3}$, Christopher F. Rose ${ }^{3}$, Jean-Christophe Leroux ${ }^{1}$

$5{ }^{1}$ Institute of Pharmaceutical Sciences, Department of Chemistry and Applied Biosciences, ETH Zurich,

6 Zurich, Switzerland

$7{ }^{2}$ Institute for Chemical and Bioengineering, Department of Chemistry and Applied Biosciences, ETH

8 Zurich, 8093, Zurich, Switzerland.

$9{ }^{3}$ Hepato-Neuro Laboratory, CRCHUM, Montréal, Québec, Canada

$10{ }^{*}$ Current address: John A. Paulson School of Engineering and Applied Sciences, Harvard University,

11 Cambridge, MA 02138, USA

13 Corresponding Author

14 Prof. Dr. Jean-Christophe Leroux

15 jleroux@ethz.ch

16 ETH Zurich

$17 \mathrm{HCl} \mathrm{H} 301$

18 Vladimir-Prelog-Weg 3

198093 Zurich

20 Switzerland

21 Tel. +41446337310

$22 \quad F a x+41446331314$

23

\section{Key words}

25 Polymersomes, poly(styrene)-b-poly(ethylene oxide), oral delivery, ammonia, hyperammonemia 


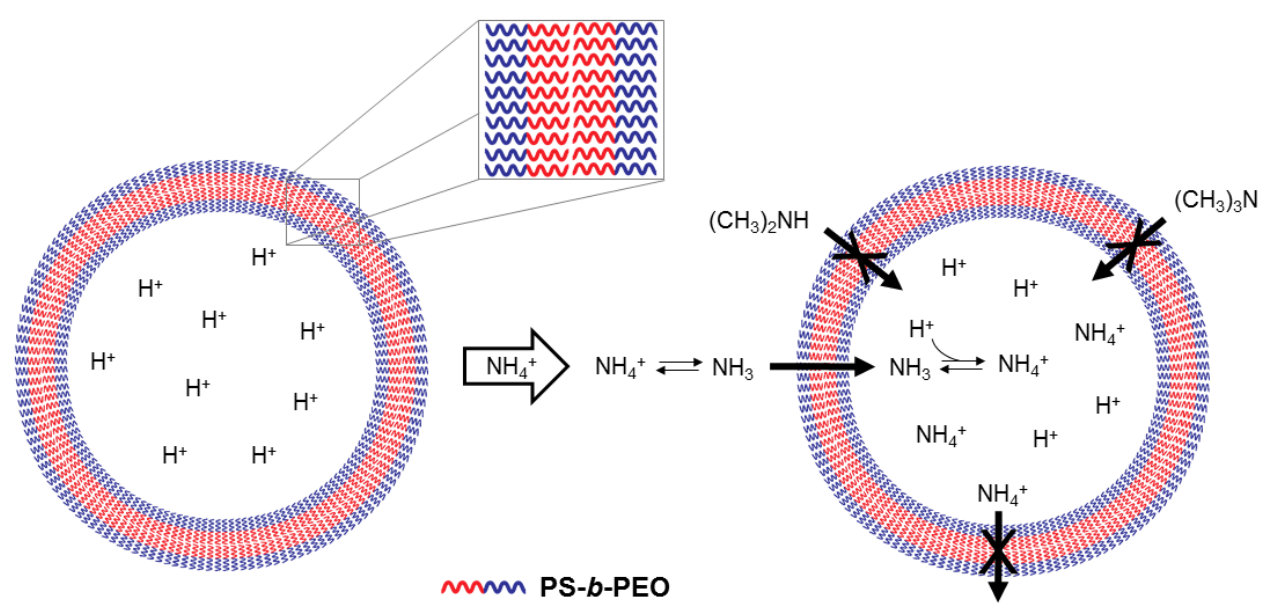

Abstract polymersomes were investigated for the oral treatment and diagnosis of hyperammonemia, a condition associated with serious neurologic complications in patients with liver disease as well as in infants with urea cycle disorders. While these polymersomes were highly stable in simulated intestinal fluids at extreme bile salt and osmolality conditions, they unexpectedly did not reduce plasmatic ammonia levels in cirrhotic rats after oral dosing. Incubation in dietary fiber hydrogels mimicking the colonic environment suggested that the vesicles were probably destabilized during the dehydration of the intestinal chyme. Our findings question the relevance of commonly used simulated intestinal fluids for studying vesicular stability. With the encapsulation of a $\mathrm{pH}$-sensitive dye in the polymersome core, the local $\mathrm{pH}$ increase upon ammonia influx could be exploited to assess the ammonia concentration in the plasma of healthy and cirrhotic rats as well as in other fluids. Due to its high sensitivity and selectivity, this novel polymersome-based assay could prove useful in the monitoring of hyperammonemic patients and in other applications such as drug screening tests. 


\section{Introduction}

Despite its important role in $\mathrm{pH}$ homeostasis and protein metabolism, the endogenous metabolite ammonia is associated with neurotoxic effects at pathologically elevated blood concentrations (hyperammonemia). ${ }^{[1,2]}$ As the liver is the main ammonia-removing organ, patients with inborn (e.g., urea cycle disorders, UCD) or acquired liver disease (e.g., liver cirrhosis, acute liver failure) often fail to efficiently clear ammonia. ${ }^{[2]}$ In consequence, ammonia accumulates in the systemic compartment, leading to neuropsychiatric symptoms in hyperammonemic patients (cognitive impairments, lethargy, hepatic coma) with a high risk of death. ${ }^{[2]}$ This syndrome termed hepatic encephalopathy (HE) affects up to $80 \%$ of patients suffering from liver cirrhosis. ${ }^{[2]}$ Current clinical practice guidelines for chronic HE patients primarily recommend treatments targeting the gut where urease-producing bacteria generate the main part of systemic ammonia. ${ }^{[3]}$ The first-line therapy lactulose is a laxative which leads to the expulsion of colonic ammonia (cathartic effect), and modulates the intestinal microbiome and $\mathrm{pH}^{\left[{ }^{[3]}\right.}$ Despite its wide use in HE patients, the number of non-responding patients is high and its laxative properties negatively affect patient compliance. ${ }^{[2]}$ The second-line treatment rifaximin, a poorly absorbed antibiotic, inhibits the growth and metabolism of gut bacteria. ${ }^{[3]}$ However, the prolonged treatment with antibiotics bears the risk of inducing bacterial resistance. ${ }^{[2]}$

In both UCD and HE, elevated plasma ammonia concentrations cause cognitive deficits and impact on clinical outcome. ${ }^{[4-8]}$ Thus, ammonia levels are routinely measured for diagnosis, disease staging, prognosis, and monitoring during ammonia-lowering treatments. ${ }^{[4-8]}$ High accuracy and precision of quantification are essential in the context of hyperammonemia given the low plasma ammonia cut-off (50 $\mu \mathrm{M}$ in adults and $100 \mu \mathrm{M}$ in newborns) and the correlation of peak ammonia levels (>200 $\mu \mathrm{M}$ in HE and UCD patients with acute hyperammonemia) with disease severity and clinical outcome. ${ }^{[3-5,9,10]}$ Yet, commonly used ammonia tests present numerous shortcomings. For instance, despite being the diagnostic gold standard, the L-glutamate dehydrogenase (GLDH)-based enzymatic assay has several interferences that are commonly found in liver disease patients (e.g., hemolysis, icterus and hyperlipidemia). ${ }^{[11]}$ Moreover, the assay has limited throughput and is prone to timing errors as it relies on an enzymatic reaction. The alternative to the GLDH assay, the strip-based handheld device PocketChem $\mathrm{BA},{ }^{[12]}$ comparably underestimates ammonia levels and has similar drawbacks: low throughput ( $3 \mathrm{~min}$ for the measurement of one sample) and interference issues (e.g., TMA and potentially other methylated ammonia analogs, Supplementary Figure 1). ${ }^{[2]}$ 
In former publications, we reported the use of transmembrane $\mathrm{pH}$-gradient lipid vesicles (liposomes) to detoxify weakly basic drugs and endogenous metabolites such as ammonia. ${ }^{[13-15]}$ These substrates diffuse across the hydrophobic membrane in their deprotonated form and are trapped upon protonation in the acidic core of the vesicle. Applied as a peritoneal dialysis solution, such liposomes efficiently sequestered ammonia and decreased plasmatic ammonia levels in bile duct-ligated (BDL) rats, an established animal model of liver cirrhosis and HE. ${ }^{[14]}$ Although liposomal peritoneal dialysis is well adapted to the management of acute HA crises in a hospital setting, an oral treatment would be more suitable for the chronic treatment and prevention of HE. Therefore, this study aimed at investigating transmembrane $\mathrm{pH}$-gradient vesicles for two other applications: the in situ detoxification of intestinal ammonia for the chronic treatment of $\mathrm{HE}$ and the quantification of ammonia in biological

A

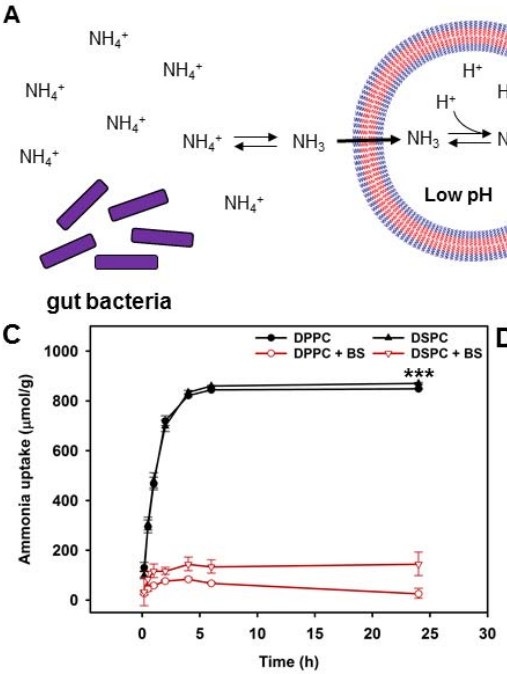

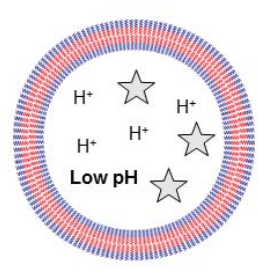

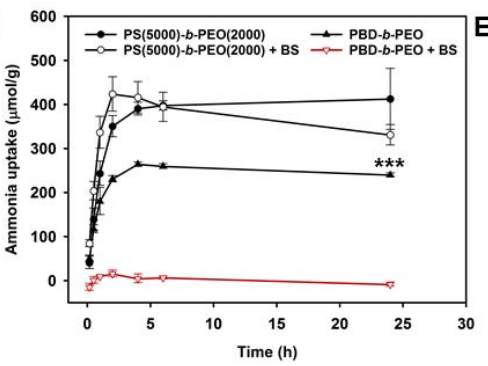

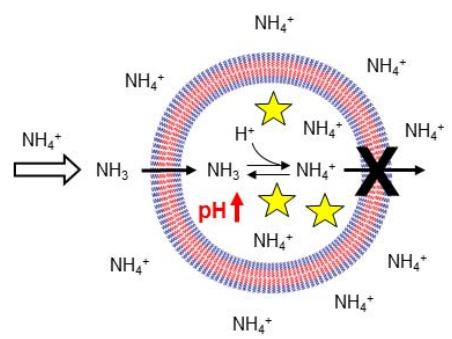

$\mathrm{NH}_{4}^{+}$

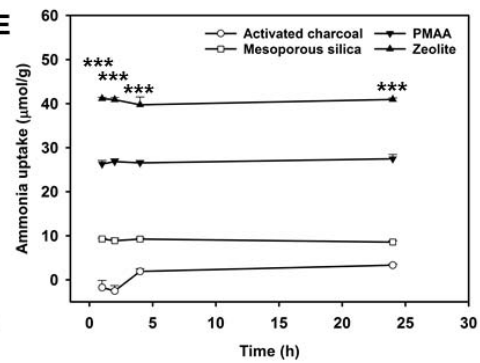

88

89

Figure 1. Ammonia sequestration by transmembrane pH-gradient lipo- and polymersomes at $\mathrm{pH} 6.8$. Schematic depiction of intestinal ammonia sequestration $(A)$ and ammonia sensing (B) using transmembrane pH-gradient polymersomes. Ammonia uptake of cholesterol-containing DPPC and DSPC liposomes at $1.75 \mathrm{mg} / \mathrm{mL}$ in isotonic buffer with or without bile salts (C). Ammonia uptake of polymersomes made of PBD(1500)- $b$-PEO(2000) or PS(5000)-b-PEO(2000) at $1.75 \mathrm{mg} / \mathrm{mL}$ in isotonic buffer with or without bile salts (D). Stars indicate significant difference in ammonia capture of vesicles in solutions with and without bile salts. Ammonia uptake of various microparticles (activated charcoal, PMAA, mesoporous silica, zeolite) at $30 \mathrm{mg} / \mathrm{mL}(\mathrm{E})$. Stars indicate significant difference of zeolite uptake from other microparticles. Buffer and bile salt composition: phosphate buffer $50 \mathrm{mM}$ at $\mathrm{pH} 6.8$; cholate, deoxycholate, taurocholate (25/25/0 mM for PBD(1500)-b-PEO(2000) polymersomes and 
bioRxiv preprint doi: https://doi.org/10.1101/631630; this version posted May 8, 2019. The copyright holder for this preprint (which was not certified by peer review) is the author/funder. All rights reserved. No reuse allowed without permission.

99 liposomes; 30/30/30 mM for PS(5000)-b-PEO(2000) polymersomes); ammonia concentration $1.5 \mathrm{mM}$;

100 temperature: $37^{\circ} \mathrm{C}$. All results as means $\pm S D(n=3) .{ }^{* * *} p<0.001$.

101 


\section{Results and Discussion}

103

104

105

106

107

108

109

110

111

112

113

114

115

116

117

118

119

120

121

122

123

124

125

126

127

128

129

130

\subsection{Stability of liposomes and polymersomes in simulated GI fluids}

The gastrointestinal (Gl) tract is a harsh environment for vesicular structures due to its high bile salt concentrations, extreme osmolarity and $\mathrm{pH}$ values, and high enzymatic activity (e.g., phospholipases $),{ }^{[16]}$ and may readily destabilize liposomes with phase transition temperatures $\left(T_{m}\right)$ below $37^{\circ} \mathrm{C}$. Therefore, liposomes with high levels of cholesterol (45\%) and relatively high $\mathrm{T}_{\mathrm{m}}$ phospholipids (1,2-dipalmitoyl-sn-glycero-3-phosphocholine, DPPC, $\mathrm{T}_{\mathrm{m}}=41^{\circ} \mathrm{C} ; 1,2$-distearoyl-snglycero-3-phosphocholine, $D S P C, \mathrm{~T}_{\mathrm{m}}=55^{\circ} \mathrm{C}$ ) were first investigated. These liposomes had a mean size in the micrometer range (Supplementary Table S1) to minimize uptake by the Gl mucosa. As shown in Figure $1 \mathrm{C}$, the ammonia uptake reached up to $800 \mu \mathrm{mol} \mathrm{NH} / \mathrm{g}$ lipids in bile salt-free buffers but was completely abolished in the presence of physiologically ${ }^{[17]}$ relevant bile salt concentrations. More resistant, non-biodegradable micrometer-sized polymeric vesicles (Supplementary Table S1) were subsequently investigated to tackle this issue. ${ }^{[18-21]}$ They were prepared by emulsification from diblock copolymers of poly(ethylene oxide) (PEO) and poly(butadiene) (PBD) or poly(styrene) (PS) having glass phase transition temperatures $\left(\mathrm{T}_{\mathrm{g}}\right)$ of $-92^{\circ} \mathrm{C}^{[22]}$ and $75^{\circ} \mathrm{C},{ }^{[23]}$ respectively. PBD- $b$-PEO polymersomes were readily destabilized by the bile salts (Figure 1D), and only the polymersomes made of the high $\mathrm{T}_{\mathrm{g}}$ diblock copolymer PS- $b$-PEO preserved their ammonia capture capacity in simulated intestinal media (Figure 1D). The capture capacity of PS- $b$-PEO polymersomes was more than 15-fold higher than that of activated charcoal microparticles (AST-120, approx. $25 \mu \mathrm{mol} \mathrm{NH}_{3} / \mathrm{g}^{[24]}$ ), an ammonia-scavenging agent, which was reported to decrease plasmatic ammonia levels in BDL rats upon oral administration. ${ }^{[24]}$ The destabilization of liposomes and PBD-b-PEO polymersomes by surfactants was likely mediated by the insertion of the amphiphiles into the bilayer and the partitioning of the amphiphilic membrane constituents into the surfactant micelles. ${ }^{[25-31]}$ In contrast, the high glass transition temperature of PS yielded a much tougher membrane. Furthermore, different microparticles were also evaluated for ammonia uptake capacity via electrostatic binding or other non-covalent interactions (e.g., aluminosilicate-based zeolites), but discarded due to their competition with physiologically relevant cations (Figure 1E, Supplementary Figure S2), and risk of inducing electrolyte imbalances in vivo. ${ }^{[32-34]}$

\subsection{Optimization of the polymersome formulation}


131 A library of bile salt-resistant PS- $b$-PEO(2000) polymersomes was subsequently prepared to select the

132 optimal PS fragment length. The ammonia uptake was preserved in polymersomes with PS fragments 133 between 2500 and 6000 over $24 \mathrm{~h}$ in a solution containing $90 \mathrm{mM}$ bile salts (Figure 2A). This bile salt 134 concentration was twice as high as extreme physiological ones, ${ }^{[17]}$ the PS- $b$-PEO polymersomes 135 further maintained their ammonia capture capacity in bile salt-containing media with pronounced hypo136 and hyperosmolalities (160 and $620 \mathrm{mOsmol} / \mathrm{kg}^{\left[{ }^{[35-37]}\right.}$ Figure 2B). Moreover, the PS-b-PEO 137 polymersomes captured ammonia in solutions containing bile salts and digestive enzymes (trypsin, 138 chymotrypsin, lipase) or large excesses of cations (Supplementary Figures S3 \& S4). To the best of 139 our knowledge, this study is the first to provide evidence on the high stability of PS- $b$-PEO 140 polymersomes with short PS fragments. One study reported that PS- $b$-PEO polymersomes composed 141 of very long PS fragments $\left(>25^{\prime} 000\right)$ were resistant to surfactants. ${ }^{[38]}$ As polymers with such large 142 hydrophobic fragments are prone to aggregation, these polymersomes are associated with low yields 143 in the vesicle preparation process (typically $<2.5 \mathrm{mg} / \mathrm{mL}$ ). ${ }^{[19,38,39]}$ In contrast, the emulsification-based 144 preparation method used in this study in conjunction with relatively short PS fragments yielded highly 145 concentrated PS- $b$-PEO polymersome dispersions with polymer concentrations exceeding 100 $146 \mathrm{mg} / \mathrm{mL}$. Furthermore, the investigation of different citric acid solutions as the inner phase pointed to an 147 isotonic citric acid solution of $250 \mathrm{mM}$ as the best compromise between ammonia capture capacity 148 and citric acid exposure (Figure 2C). Finally, cryo-SEM analysis confirmed the vesicular morphology of 149 the PS-b-PEO polymersomes (see arrows, Figure 2D). 

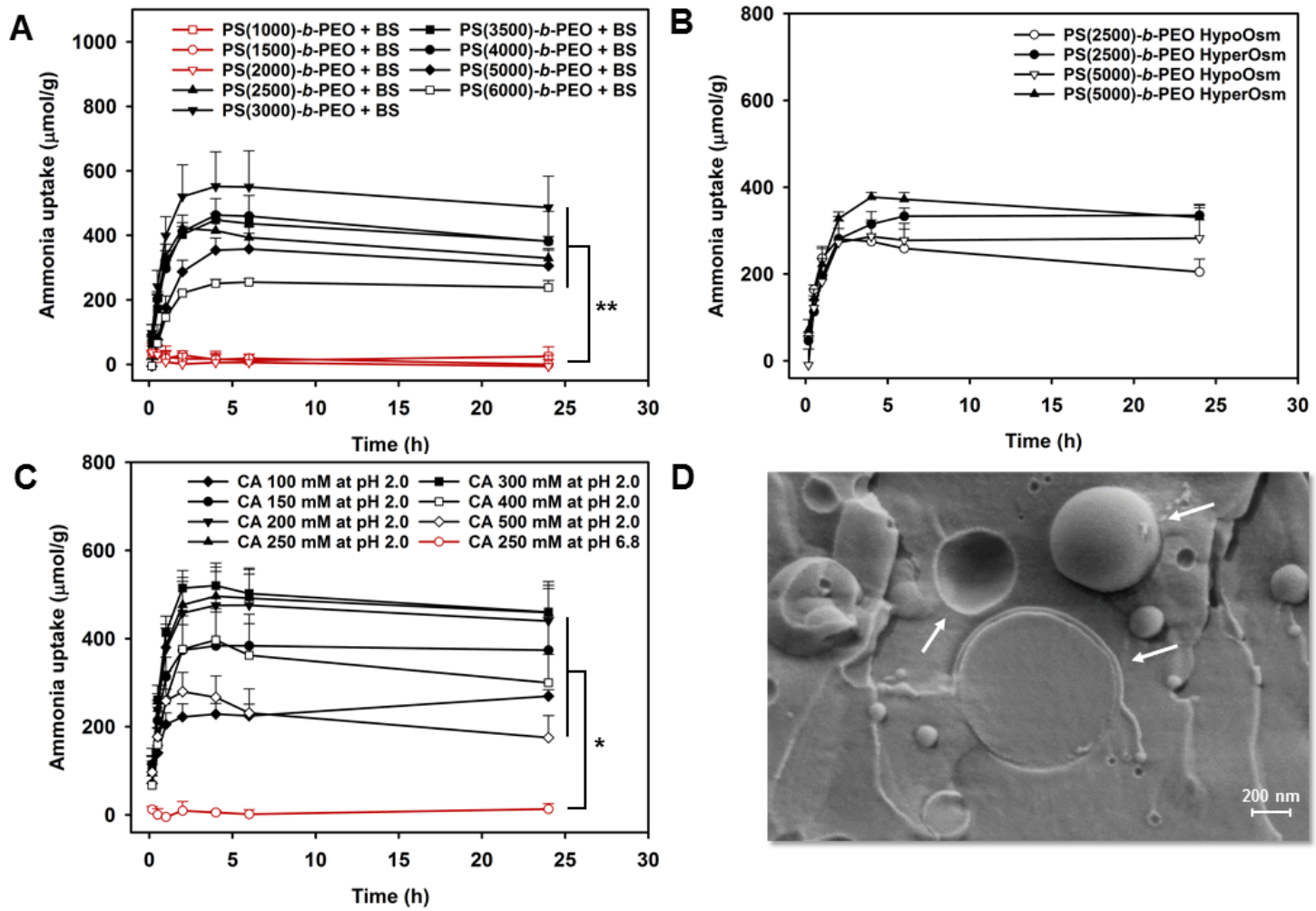

Figure 2. Ammonia uptake and characterization of PS- $b$-PEO polymersomes. Ammonia uptake of PS$b$-PEO(2000) polymersomes with PS fragments between 1000 and 6000 in bile salt-containing buffer (A). Ammonia uptake of PS(2500)- $b$-PEO(2000) and PS(5000)-b-PEO(2000) polymersomes incubated in hypo- (160 mOsmol/kg) and hyperosmolal $(620 \mathrm{mOsmol} / \mathrm{kg})$ bile salt-containing buffer (B). Ammonia uptake of PS- $b$-PEO polymersomes with different citric acid concentrations in the core (100 to $500 \mathrm{mM}$ ) at $\mathrm{pH} 2.0$ and control PS- $b$-PEO polymersomes without a transmembrane $\mathrm{pH}$-gradient (core pH 6.8) in bile salt-containing buffer (C). Cryo-SEM image of PS(3300)-b-PEO(2000) polymersomes in isotonic citric acid solution $250 \mathrm{mM}$ at pH 2.0 (D). Buffer and bile salt composition: phosphate buffer $50 \mathrm{mM}$ at $\mathrm{pH}$ 6.8; cholate, deoxycholate, taurocholate $(30 / 30 / 30 \mathrm{mM}$ in all conditions except hypoosmolal conditions (25/25/0 mM)); ammonia concentration $1.5 \mathrm{mM}$; temperature: $37^{\circ} \mathrm{C}$. All results as means $\pm \mathrm{SD}(\mathrm{n}=3(\mathrm{~A}, \mathrm{~B}), \mathrm{n}=3-8, \mathrm{C}) .{ }^{*} p<0.05$ and ${ }^{* *} p<0.01$.

\subsection{Stability of polymersomes in dietary fiber hydrogels}

To investigate the stability of the polymersomes under colon-mimicking conditions, a novel dietary fiber-based in vitro assay was established. PS- $b$-PEO(2000) polymersomes were incubated in dietary fiber (Metamuci ${ }^{\circledR}$, psyllium husk) hydrogels at fiber concentrations reaching physiologically relevant stool water contents (approx. 50\%, $\mathrm{m} / \mathrm{m}$ ), simulating the thickening of the feces in the colon due to water resorption. In other studies where liposomes were incorporated in hydrogels for drug delivery applications, the concentration of hydrogel-forming agents was typically much lower (approx. 2\%, $\mathrm{m} / \mathrm{m}$ ) than the one used here (up to $50 \%, \mathrm{~m} / \mathrm{m}$ ). ${ }^{[40-42]}$ After $24 \mathrm{~h}$ of incubation, the polymersomes 
170 showed a fiber concentration-dependent decrease in ammonia capture capacity (Figure 3A). To

171 investigate the destabilization mechanism in detail, the $\mathrm{pH}$-dependent fluorescent dye 8-

172 hydroxypyrene-1,3,6-trisulfonate (HPTS) was encapsulated in transmembrane pH-gradient

173 polymersomes. With increasing fiber content, the fluorescence emission ratio (i.e., emission at $\lambda_{\mathrm{em}}$

$174(510 \mathrm{~nm})$ using $\mathrm{pH}$-dependent $\lambda_{\mathrm{ex}}(413 \mathrm{~nm})$ normalized to emission at the same $\lambda_{\mathrm{em}}$ using the

175 isosbestic $\lambda_{\mathrm{ex}}, 455 \mathrm{~nm}$ ) of HPTS increased (Figure 3B), indicating a pH increase in the environment

176 around the fluorescent dye (i.e., loss of $\mathrm{pH}$-gradient and/or efflux of dye). ${ }^{[43]}$ The disruption of the

177 polymersome membrane was confirmed after encapsulating the dye/quencher pair HPTS/p-xylene-

178 bis-pyridinium bromide (DPX) in the polymersome core, and observing an increase in HPTS

179 fluorescence emission after hydrogel incubation (Figure $3 C$ ) ${ }^{[44]}$ The polysaccharide-based hydrogel-

180 forming dietary fibers probably bound a large fraction of the free water molecules, resulting in a strong

181 osmolality increase and a subsequent destabilization of the membrane. The comparably high water

182 permeability of PS could allow an outflow of water in extremely hyperosmolal environments which may

183 impair the polymersomes' membrane integrity and result in the loss of the transmembrane $\mathrm{pH}$ -

184 gradient. ${ }^{[19,45]}$ In addition, the ordered structure of the hydrogel might cause mechanical stress on the

185 polymersome membrane, especially with regard to the large size of the polymersomes. ${ }^{[46]} \mathrm{A}$ decrease

186 in vesicle size might improve stability but bears the risk of increased uptake by $\mathrm{M}$ cells in the gut. ${ }^{[4]}$

187 While longer hydrophobic block lengths may make the polymersomes more resistant, their

188 hydrophobicity could complicate the preparation of highly concentrated polymersome

189 dispersions. ${ }^{[19,38,39]}$ Although PS- $b$-PEO polymersomes were stable in simulated intestinal fluids

190 pushed to extreme bile salt and osmolality conditions, the instabilities detected in the dietary fiber

191 assay cast doubt on the relevance of commonly used simulated intestinal fluids in the assessment of

192 vesicular stability in the GI tract. ${ }^{[30,48,49]}$
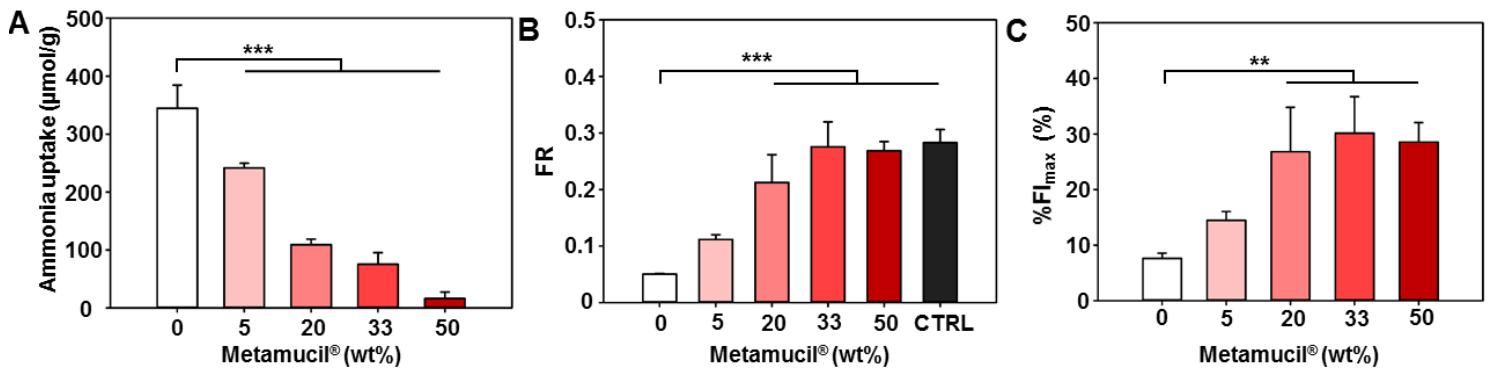

Figure 3. Stability of PS- $b$-PEO polymersomes in dietary fiber (Metamucil ${ }^{\circledR}$ )-based hydrogels.

195 Ammonia uptake of transmembrane $\mathrm{pH}$-gradient PS- $b$-PEO(2000) polymersomes after $24 \mathrm{~h}$ incubation

196 in dietary fiber-based hydrogels at different fiber concentrations (A). Fluorescence emission ratio (FR, 
197

198

199

200

201

202

203

204

205

206

207

208

209

210

211

212

213

214

215

216

217

218

219

220

221

222

223

224

225

226

227

emission at $\lambda_{\mathrm{em}}(510 \mathrm{~nm})$ using $\mathrm{pH}$-dependent $\lambda_{\mathrm{ex}}(413 \mathrm{~nm})$ normalized to emission at the same $\lambda_{\mathrm{em}}$ using the isosbestic $\lambda_{\mathrm{ex}}, 455 \mathrm{~nm}$ ) of HPTS-containing transmembrane $\mathrm{pH}$-gradient PS- $b$-PEO polymersomes after $24 \mathrm{~h}$ incubation in dietary fiber-based hydrogels (B). Normalized fluorescence intensity $\left(\% \mathrm{FI}_{\max }\right)$ of DPX/HPTS-containing polymersomes after $24 \mathrm{~h}$ incubation in dietary fiber-based hydrogels (C). PS fragment length: $3300-4500 \mathrm{~g} / \mathrm{mol}$; concentration of polymer $(1 \mathrm{mg} / \mathrm{mL}, A)$ or dye $(50 \mu \mathrm{M}, \mathrm{B}, 30 \mu \mathrm{M}, \mathrm{C})$ in final dispersion; buffer composition: isotonic phosphate buffer at pH $6.8(\mathrm{~A}-\mathrm{C})$; inner phase citric acid solution $250 \mathrm{mM}$ at pH 2.0 (A, B, except for non-pH gradient control $(\mathrm{pH}$ 6.8) in $B$ ), isotonic phosphate buffer at $\mathrm{pH} 6.8(\mathrm{C})$; temperature $37^{\circ} \mathrm{C} ; \mathrm{n}=3$. All results as means $\pm \mathrm{SD} .{ }^{* *} p<$ 0.01 and ${ }^{* *} p<0.001$.

\subsection{Oral application of PS-b-PEO polymersomes}

The PS- $b$-PEO polymersomes were orally administered to investigate their ammonia-scavenging capacity in vivo. In the light of the reduced stability of PS- $b$-PEO polymersomes in a simulated colon environment in vitro, laxative agents (PEG, sodium picosulfate) were orally applied to the BDL rats as an add-on to the polymersomes in order to hydrate the intestine. In contrast to PEG (1 g/kg), sodium picosulfate $(25 \mathrm{mg} / \mathrm{kg})$ significantly increased the stool water content compared with the water-only control over a period of $24 \mathrm{~h}$ (Figure $4 \mathrm{~A}$ ) in BDL rats. Hence, the efficacy of orally applied PS- $b$-PEO polymersomes was subsequently investigated in the presence of sodium picosulfate in BDL rats at 21 days after surgery with a seven-day twice-daily ( $1 \mathrm{~g} / \mathrm{kg}$ per day) treatment (Figure 4B). The plasmatic ammonia levels were significantly increased in BDL rats at day 28 compared to non-BDL control rats. However, when comparing the two BDL groups, the plasma levels of the polymersome and the citric acid control group were not significantly different (Figure 4C). We hypothesize that the increase in stool hydration provided by the laxative was insufficient to prevent the destabilization of the polymersomes in the intestinal environment as they lose two thirds of their ammonia capture capacity in a dietary fiber hydrogel with a water content of $80 \%(\mathrm{~m} / \mathrm{m}$, i.e., fiber content $20 \%(\mathrm{~m} / \mathrm{m})$, Figure $3 \mathrm{~A})$. The polymersome stability could potentially be improved by further increasing the laxative dose. However, excessive fluid and electrolyte losses could limit such a dose elevation. The present study shows that vesicles, which appear stable under highly challenging in vitro conditions, may still be destabilized in the GI tract, especially as the chyme becomes dehydrated. Therefore, more in-depth studies are warranted to investigate the stability of vesicular carriers in the GI tract, especially when they are used to deliver labile drugs such as insulin via the oral route. ${ }^{[16]}$ 

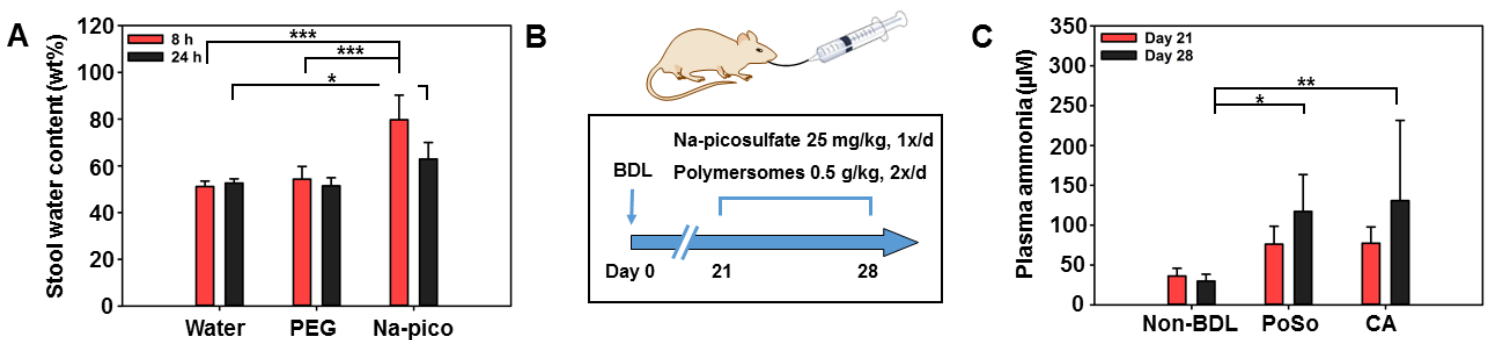

229

230

231

232

233

234

235

236

237

238

239

240

241

242

243

Figure 4. In vivo of PS- $b$-PEO polymersomes evaluation in BDL rats. Stool water content in male Sprague-Dawley rats 21 days after BDL surgery gavaged with water $(5 \mathrm{~mL} / \mathrm{kg})$, PEG (3350) (PEG, 1 $\mathrm{g} / \mathrm{kg}$ ), or sodium picosulfate $(25 \mathrm{mg} / \mathrm{kg}$ ) for at least two days ( $\mathrm{n}=3-19$ stool samples) (A). Study plan: three weeks after BDL surgery, two groups of cirrhotic rats ( $n=16-17$ per group) received sodium picosulfate (once daily, $25 \mathrm{mg} / \mathrm{kg}$ ) and polymersome dispersion in citric acid solution (twice daily, $0.5 \mathrm{~g}$ PS- $b$-PEO(2000) polymer $/ \mathrm{kg}$; PS fragment length: $2800-5500 \mathrm{~g} / \mathrm{mol}$ ) or citric acid solution alone (twice daily $0.24 \mathrm{~g}$ citric acid $/ \mathrm{kg}$ ) by gavage for one week. A group of age-matched healthy control rats $(\mathrm{n}=$ 6) received citric acid solution (twice daily $0.24 \mathrm{~g} / \mathrm{kg}$ ) by gavage for one week (B). Plasma ammonia levels in BDL rats at 21 days (saphenous vein) and at sacrifice at 28 days (cardiac puncture) after BDL surgery (polymersome group $n=16$, citric acid group $n=17$ ) and in age-matched healthy controls (non-BDL control group $\mathrm{n}=6, \mathrm{C}$ ). All results as means $\pm \mathrm{SD}$. ${ }^{*} p<0.05,{ }^{* *} p<0.01$, and ${ }^{* * *} p<0.001$.

\subsection{Ammonia sensing with polymersomes}

\subsubsection{Dye selection and characterization of polymersome-based ammonia assay}

Notwithstanding, the transmembrane $\mathrm{pH}$-gradient polymersomes may constitute a valuable diagnostic tool for HE and UCD, since adequate and affordable assays for the quantification of ammonia in biological solutions are still missing. Encapsulating the pH-sensitive dye HTPS in the polymersome core enabled the quantification of the increase in luminal $\mathrm{pH}$ upon ammonia influx and the determination of the extravesicular ammonia concentration (Figure 1B). As for the oral application, very high selectivity and stability of the vesicles are required for the diagnostic application. HPTS was selected due to its $\mathrm{pH}$-responsive fluorescence excitation spectrum (Supplementary Figure S5) and its high hydrophilicity (three negative charges) which hinders its leakage. In addition, the isosbestic excitation wavelength allows for a correction of slight differences in dye concentration.

HPTS-containing PS- $b$-PEO polymersomes showed a linear ammonia sensing profile in the physiologically relevant range of 12.5 to $800 \mu \mathrm{M}$ (Figure $5 \mathrm{~A}$ ). The concentrations of the calibration standards could be back-calculated with high accuracy and precision both below (non- 
hyperammonemic to moderately hyperammonemic region) and above $200 \mu \mathrm{M}$ (highly hyperammonemic region) by splitting the linear regression curve or adjusting the volume fraction of the ammonia standard (Supplementary Figure S6, Supplementary Table S2). The linear range and coefficient of determination of the polymersome assay were comparable or possibly superior to the reported parameters for commercial or investigative ammonia tests such as the GLDH-based enzymatic assay and the PocketChem BA (Supplementary Figures S7 \& S8, Supplementary Table S3). Under the investigated conditions, the lower limit of quantification was as low as $27 \mu \mathrm{M}$. Both a low and a high volume fraction of the ammonia standards showed a low time dependence of the fluorescence intensity ratio after $10 \mathrm{~min}$ at room temperature (Figure $5 \mathrm{~B}$ ) which points to the usefulness of the assay for high throughput screenings. Furthermore, PS- $b$-PEO polymersomes remained sensitive to ammonia after five months of storage in an isotonic phosphate buffer at $\mathrm{pH} 7.4$ and $4^{\circ} \mathrm{C}$ (Supplementary Figure S9), highlighting the stability of the transmembrane $\mathrm{pH}$ gradient over time.

A

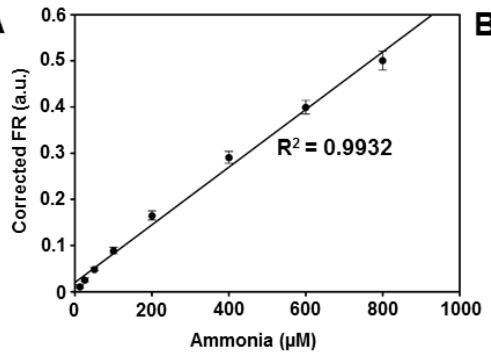

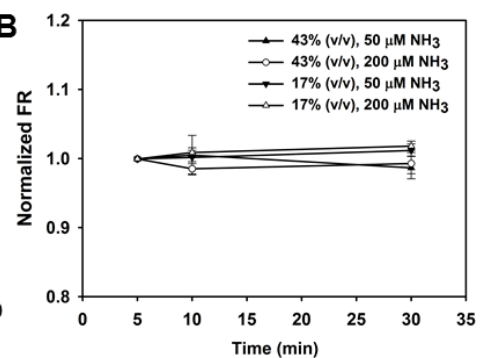

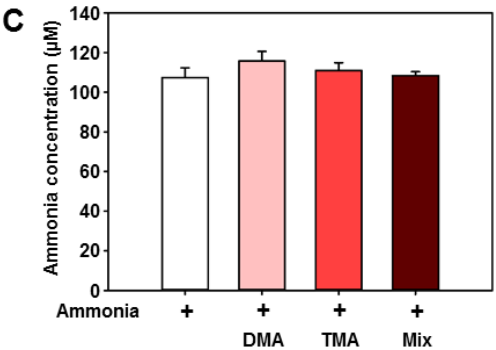

269

270

271

272

273

274

275

276

277

278

279

280

281

282

283

Figure 5. Ammonia sensing with HPTS-containing PS-b-PEO polymersomes. Blank-corrected fluorescence emission ratio (FR) of HPTS-loaded polymersomes at different ammonia concentrations (A). Normalized FR (FR at given time point normalized to FR at $5 \mathrm{~min}$ ) of polymersomes exposed to 50 or $200 \mu \mathrm{M}$ after 10 and $30 \mathrm{~min}$ incubation at room temperature. No statistically significant differences were observed between $10 \mathrm{~min}$ and $30 \mathrm{~min}$ for a given ammonia concentration and volume fraction of standard. Ammonia concentrations measured using the polymersome assay upon coincubating ammonia $(100 \mu \mathrm{M})$ with DMA $(200 \mu \mathrm{M})$, TMA $(100 \mu \mathrm{M})$, or a mixture (Mix) of drugs and endogenous compounds (levofloxacin, propranolol, glycine, alanine, dopamine, each at $500 \mu \mathrm{M})(\mathrm{C}$ ). No significant differences were observed between the ammonia concentrations determined in the absence and presence of the tested potentially interfering substances. Inner phase: isotonic citrate buffer $5 \mathrm{mM}$ at $\mathrm{pH}$ 5.5; outer phase: isotonic phosphate buffer $50 \mathrm{mM}$ at $\mathrm{pH}$ 7.4. HPTS concentration in final dispersion: $16 \mu \mathrm{M}(\mathrm{A}-\mathrm{C}), 40 \mu \mathrm{M}$ (B). Sample/standard volume fraction: $17 \%$ (A-C), $43 \%$ (B); PS fragment length: $2800-4500 \mathrm{~g} / \mathrm{mol}$; FR: emission at $\lambda_{\mathrm{em}}(510 \mathrm{~nm})$ using $\mathrm{pH}$-dependent $\lambda_{\mathrm{ex}}(413 \mathrm{~nm})$ normalized to emission at the same $\lambda_{\mathrm{em}}$ using the isosbestic $\lambda_{\mathrm{ex}}(455 \mathrm{~nm})$. All results as mean $\pm \mathrm{SD}$ ( $\mathrm{n}$ $=3$ ). 


\subsubsection{Selectivity of the polymersome assay}

285 To assess the selectivity of the polymersome assay, PS- $b$-PEO polymersomes were co-incubated with 286 amine-containing weakly basic substances (Supplementary Table S4). The di- and tri-methylated analogs of ammonia (dimethylamine, DMA, and trimethylamine, TMA, respectively) were chosen because of their structural similarity to ammonia and their physiological relevance ${ }^{[50,51]}$ Even at concentrations exceeding physiological serum concentrations by more than 25 -fold ${ }^{[50,51]}$ DMA and TMA did not significantly influence the measured ammonia concentration (Figure 5C). Moreover, a mixture of drugs and metabolites (levofloxacin, propranolol, glycine, alanine, dopamine, each in fivefold molar excess over ammonia) did not interfere with the ammonia assay. PS- $b$-PEO polymersomes therefore selectively sequestered ammonia in the presence of weakly basic molecules that were shown to interfere with ammonia uptake in liposomes. ${ }^{[15,52]}$ The highly hydrophobic, rigid membrane of PS- $b$-PEO polymersomes probably hinders the diffusion of bulkier and more hydrophilic substrates than ammonia.

\subsubsection{Ammonia sensing in rat plasma}

To evaluate the polymersome assay in plasma of healthy and BDL rats, the ammonia concentrations determined by the polymersome assay, the GLDH-based test, and the PocketChem BA were compared. In healthy rat plasma, the three tests performed similarly except for two hemolyzed samples in which the GLDH assay overestimated the ammonia levels compared with the other two tests (Figure 6A, Supplementary Figure S10). Hemolysis is a reported interference of the GLDH assay. ${ }^{[11]}$ In plasma of BDL rats, which exhibit typical pathological changes in biochemical laboratory parameters of liver cirrhosis (Supplementary Table S5), ${ }^{[11,14]}$ an interference in the polymersome assay was observed (Supplementary Figure S11), probably due to the high bilirubin levels. Indeed, bilirubin exhibits a broad fluorescence emission peak around $525 \mathrm{~nm}$ when excited at $455 \mathrm{~nm} .{ }^{[53]}$ Lowering the sample volume fraction to $17 \%$ (i.e., diluting the bilirubin) yielded similar results compared with the GLDH assay (Figure 6B). Alternatively, this interference might be circumvented by the replacement of HPTS with a pH-sensitive near-infrared dye which could further enable ammonia sensing in whole blood. In accordance with the literature, the PocketChem BA yielded significantly lower ammonia levels than the GLDH assay. ${ }^{[12]}$ 
A

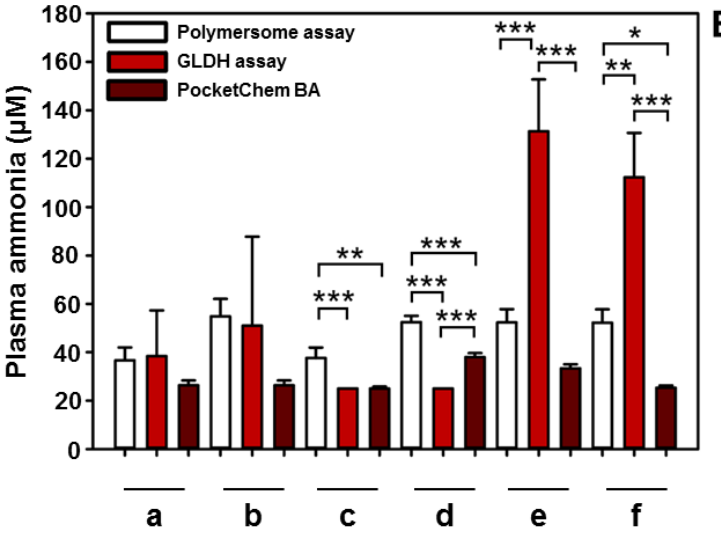

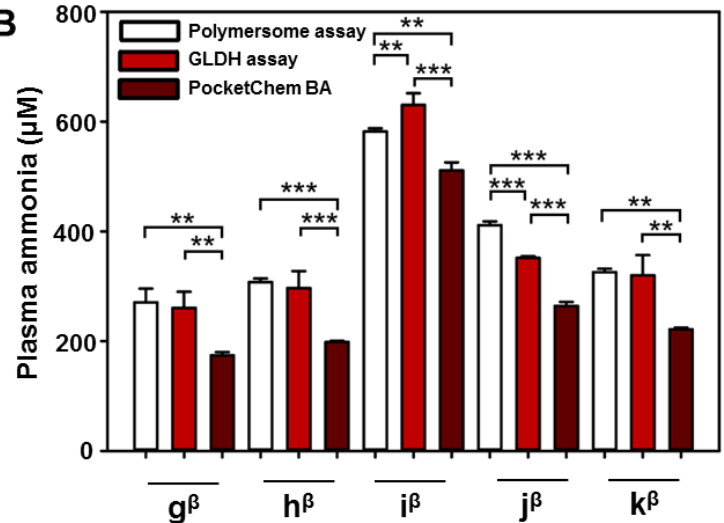

313

314

315

316

317

318

319

320

321

322

323

324

325

326

327

328

329

330

331

332

Figure 6. Ammonia sensing in rat plasma. Arterial plasma samples (cardiac puncture) from healthy (A) and BDL ( $\beta$, four weeks after surgery, $B$ ) male Sprague-Dawley rats measured with the polymersome assay, GLDH-based ammonia assay, and PocketChem BA. Each letter (a-k) on the x-axis represents one animal. Inner phase: isotonic citrate buffer $5 \mathrm{mM}$ at pH 5.5; outer phase: isotonic phosphate buffer $50 \mathrm{mM}$ at $\mathrm{pH}$ 7.4. HPTS concentration in final dispersion: $40 \mu \mathrm{M}(\mathrm{A}), 16 \mu \mathrm{M}(\mathrm{B})$. Sample/standard volume fraction: $43 \%$ (A), 17\% (B); PS fragment length: $2800-4500 \mathrm{~g} / \mathrm{mol}$; FR: emission at $\lambda_{\mathrm{em}}(510$ $\mathrm{nm}$ ) using $\mathrm{pH}$-dependent $\lambda_{\mathrm{ex}}(413 \mathrm{~nm})$ normalized to emission at the same $\lambda_{\mathrm{em}}$ using the isosbestic $\lambda_{\mathrm{ex}}$ (455 nm). All results as mean \pm SD $(n=3-10) .{ }^{*} p<0.05,{ }^{* *} p<0.01$, and ${ }^{* * *} p<0.001$.

\subsubsection{Ammonia sensing in other biological fluids}

Interestingly, the polymersome-based ammonia assay was not limited to the determination of plasmatic ammonia levels in hyperammonemia. The polymersome assay was successfully used to quantify ammonia in various human body fluids such as saliva, urine, sweat, and semen upon lowering the sample volume fraction (Figure 7A). It was also capable of discriminating ammonia-spiked intestinal fluid samples (Figure 7B), which could be of interest in the establishment of a highthroughput screening for urease inhibitors. Furthermore, co-incubating the polymersomes with Lphenylalanine ammonia-lyase, which converts L-phenylalanine to ammonia and trans-cinnamic acid, enabled the quantification of phenylalanine (Supplementary Figure S12). The plasma levels of this amino acid are elevated in phenylketonuria, a hereditary disease caused by phenylalanine hydroxylase deficiency. ${ }^{[54]}$ 

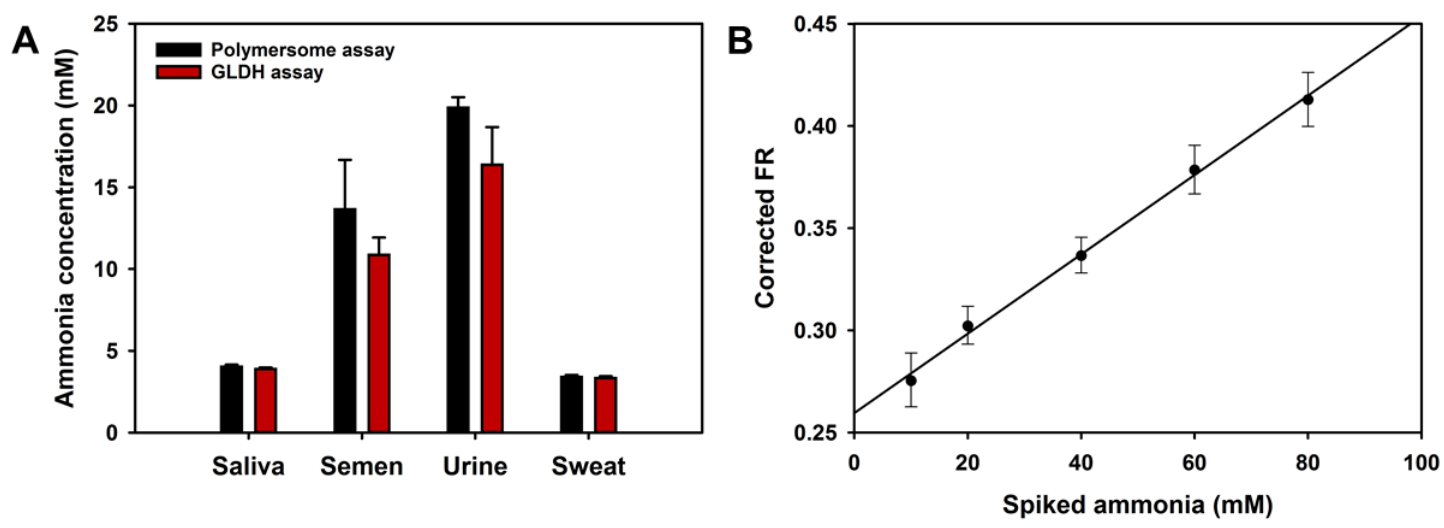

333

334

335

336

337

338

339

340

341

342

Figure 7. Ammonia sensing in various biological fluids. Ammonia concentration determined by the polymersome- and GLDH-based ammonia assays in human saliva, semen, urine, and sweat (A). No statistically significant differences were observed between the two ammonia assays. Baselinecorrected fluorescence emission ratio of HPTS-containing polymersomes in rat caecum fluid spiked with ammonium chloride (B). PS fragment length: 2800 (A), 4100 (B). Inner phase: isotonic citrate buffer $5 \mathrm{mM}$ at $\mathrm{pH} 5.5$, outer phase: isotonic phosphate buffer $50 \mathrm{mM}$ at $\mathrm{pH} 7.4$. HPTS concentration in final dispersion: $16 \mu \mathrm{M}$. Volume fraction of sample: $0.17 \%$ (semen, urine), $1.7 \%$ (saliva, sweat) (A), $0.5 \%$ (B). Corrected fluorescence emission ratio (FR): FR of blank subtracted from FR at given spiked ammonia concentration. All results as mean $\pm \operatorname{SD}(n=3)$. 


\section{3. Conclusion}

344 In conclusion, PS- $b$-PEO polymersomes represent a promising sensitive and selective system for the 345 monitoring of ammonia levels in plasma and various other body fluids, relevant for disease diagnosis

346 and drug candidates screening. Despite being resistant to commonly used simulated intestinal fluids 347 (bile salts, extreme osmolality conditions, digestive enzymes), these vesicles were destabilized under 348 colon-mimicking conditions in vitro and in BDL rats in vivo. These results cast doubt on the relevance 349 of such simulated intestinal fluids for studying the stability and predicting the release kinetics of 350 vesicular delivery systems in the GI tract. 


\section{Experimental section}

353

354

355

356

357

358

359

360

361

362

363

364

365

366

367

368

369

370

371

372

373

374

375

376

377

378

379

380

\subsection{PS- $b$-PEO polymer synthesis and characterization}

Poly(styrene)- $b$-poly(ethylene oxide) (PS- $b$-PEO(2000)) polymers were bought from Advanced Polymer Materials (Dorval, QC, Canada; Supplementary Table S6) or synthesized by atom transfer radical polymerization (ATRP, Supplementary Table S7). ${ }^{[55]}$ PEO(2000) monomethyl ether (SigmaAldrich Chemie, Buchs, Switzerland) was converted to an ATRP macroinitiator by reacting it with 2bromopropionyl bromide (Sigma-Aldrich Chemie) in dry tetrahydrofuran (Acros Organics, New Jersey, $\mathrm{NJ}$ ) and further used to polymerize styrene (Sigma-Aldrich Chemie) in bulk. Briefly, the ATRP macroinitiator $(2.0 \mathrm{mmol})$ was loaded in a flame-dried Schlenk flask, along with copper bromide $(\mathrm{CuBr}$, 3.0 mmol Alfa Aesar, Ward Hill, MA) and 4,4'-dinoyl-2,2'-dipyridyl (2.64 mmol, TCl, Tokyo, Japan) as the catalyst and ligand, respectively. The Schlenk flask was evacuated and refilled with argon for several cycles to remove oxygen. In a separate flask, styrene $(100 \mathrm{mmol}, 11.5 \mathrm{~mL}$, Sigma-Aldrich Chemie) was deoxygenated by argon bubbling for $0.5 \mathrm{~h}$, and then loaded in the Schlenk flask. The mixture was then heated at $115^{\circ} \mathrm{C}$ during $16 \mathrm{~h}$ and the solution containing the black product was dissolved in THF, filtered through a basic alumina column and precipitated twice in hexane. The precipitate was collected and dried under vacuum. The feeding molar ratio of [monomer]/[initiator] of 50 was used to achieve PS(4000)-b-PEO(2000). The PS/PEO composition was determined in deuterated acetone by ${ }^{1} \mathrm{H}$ NMR (Bruker AV-400, Billerica, MA) at room temperature (Supplementary Figure S13).

For the molecular weight and dispersity $(\bigoplus)$ determination of the PS- $b$-PEO diblock co-polymers (Supplementary Table S7), the polymers were dissolved in THF at $2 \mathrm{mg} / \mathrm{mL}$ and characterized by gelpermeation chromatography with the same organic solvent $(0.5 \mathrm{~mL} / \mathrm{min})$ as mobile phase equipped with two ViscoGEL columns (GMHHR-M, poly(styrene-co-divinylbenzene)) at $35^{\circ} \mathrm{C}$ and coupled to a refractive index detector (Viscotec GPCmax VE-2001 with Viscotek TDA 302 Triple Detector Array, Viscotek, Malvern Panalytical, Malvern, UK) using poly(methylmethacrylate) standards (2500 - 89300 , PSS Polymer Standards Service, Mainz, Germany).

\subsection{Polymersome preparation}

PBD(2500)-b-PEO(1500) (number-averaged molecular weights, Đ 1.04, Polymer Source, Dorval, Canada) and PS- $b$-PEO polymersomes were produced using an oil-in-water (o/w) emulsification 
381

382

383

384

385

386

387

388

389

390

391

392

393

394

395

396

397

398

399

400

401

402

403

404

405

406

407

408

409

method. All polymers (60 mg) except PS(6000)- $b$-PEO(2000) were dissolved in $100 \mu \mathrm{L}$ of dichloromethane (Sigma Aldrich Chemie). PS(6000)-b-PEO(2000) (20 mg) was dissolved in $100 \mu \mathrm{L}$ of toluene (Sigma Aldrich Chemie). PS-b-PEO(2000) polymers of different PS fragment length were never pooled prior to polymersome preparation. The polymer solution was added dropwise to $1 \mathrm{~mL}$ citric acid (Sigma Aldrich Chemie) solution $250 \mathrm{mM}$ at pH 2.0 at $300 \mathrm{mOsmol} / \mathrm{kg}$ (unless stated otherwise) under sonication in an ice bath using the following parameters: amplitude 70 , cycle 0.75 (UP200H, 200W, 24 kHz equipped with sonotrode S1, Hielscher Ultrasonics, Teltow, Germany) for 3 min or amplitude 10 (3.1 mm sonotrode, Fisher Scientific Model 705 Sonic Dismembrator, 700W, 50/60 Hz, Fisher Scientific, Reinach, Switzerland) for $2 \mathrm{~min}$. The organic solvent was evaporated with a rotary evaporator for at least $5 \mathrm{~min}$ at $40^{\circ} \mathrm{C}$ at $70 \mathrm{kPa}$.

In the scaled-up method, $1.84 \mathrm{~g}$ PS- $b$-PEO polymer (diblock copolymers from Supplementary Table S7; PS- $b$-PEO polymer batches with different PS fragment length were never pooled prior to polymersome preparation) were dissolved in $1.84 \mathrm{~mL}$ dichloromethane. The polymer solution was added dropwise to $16 \mathrm{~mL}$ citric acid solution $250 \mathrm{mM}$ at pH 2.0 at $300 \mathrm{mOsmol} / \mathrm{kg}$ under sonication in an ice bath using the following parameters: initial amplitude $50(6 \mathrm{~mm}$ sonotrode, Fisher Scientific Model 705 Sonic Dismembrator) during the addition of the oil phase (approx. $1 \mathrm{~min}$ ) and subsequent sonication at amplitude 60 for another $3 \mathrm{~min}$. The organic solvent was evaporated using a rotary evaporator for at least $10 \mathrm{~min}$ at $40{ }^{\circ} \mathrm{C}$ at $60 \mathrm{kPa}$. The polymersome batches were subsequently pooled. The concentration of dichloromethane in the pooled polymersome batches was further reduced by rotary evaporation at $40{ }^{\circ} \mathrm{C}$ and $22 \mathrm{kPa}$ for 8 to $13 \mathrm{~h}$. The residual dichloromethane content as determined by head-space gas chromatography (see section 4.3.2) ranged between 0.13 and $0.33 \mathrm{mg} / \mathrm{mL}$.

The preparation of fluorescent PS- $b$-PEO polymersomes was conducted similarly to the low-volume protocol with a modified polymer amount $(30 \mathrm{mg})$ and buffer composition. For the ammonia sensing experiments, an isotonic citric acid solution $5 \mathrm{mM}$ at pH 5.5 containing $10 \mathrm{mM}$ HPTS was chosen. For the dietary fiber hydrogel experiments (see section 4.6), an isotonic citric acid solution $250 \mathrm{mM}$ at $\mathrm{pH}$ 2.0 containing HPTS $10 \mathrm{mM}$ was used for the preparation of HTPS-containing transmembrane $\mathrm{pH}$ gradient polymersomes. As a control, non- $\mathrm{pH}$ gradient polymersomes containing an isotonic phosphate buffer $10 \mathrm{mM}$ and HPTS $10 \mathrm{mM}$ at $\mathrm{pH} 6.8$ as the inner phase were prepared. For the 
410 preparation of HPTS/DPX-containing polymersomes, and an isotonic phosphate buffer $50 \mathrm{mM}$ at $\mathrm{pH}$

4116.8 containing HPTS $10 \mathrm{mM}$ and $p$-xylene-bis( $N$-pyridinium bromide) (DPX) $30 \mathrm{mM}$ was selected.

412 The fluorescent polymersomes were purified using MidiTrap G-25 columns (GE Healthcare Europe,

413 Freiburg i. Br., Germany) to remove the free dye and exchange the external phase with an isotonic 414 sodium chloride-containing phosphate buffer (ammonia sensing: phosphate concentration $50 \mathrm{mM}, \mathrm{pH}$

415 7.4; hydrogel experiments: phosphate concentration $10 \mathrm{mM}, \mathrm{pH} 6.8) \cdot{ }^{[44]}$ In brief, after washing the 416 column three times with the final buffer of choice, $200 \mu \mathrm{L}$ of HPTS-containing polymersome dispersion 417 and $800 \mu \mathrm{L}$ of buffer solution were added to the column. The purified fluorescent polymersomes were 418 eluted with $600 \mu \mathrm{L}$ of buffer and stored at $4{ }^{\circ} \mathrm{C}$ protected from light.

\subsection{Characterization of the polymersomes}

\subsubsection{Concentration of polymer in the polymersome dispersions}

421 The polymer concentration of PS-b-PEO was determined by spectrophotometry. The dispersion was 422 diluted in $\mathrm{N}, \mathrm{N}$-dimethylformamide (final polymersome dispersion concentration $5 \%(\mathrm{v} / \mathrm{v})$ and $2.5 \%(\mathrm{v} / \mathrm{v}$ ) 423 for $1 \mathrm{~mL}$ and for $16 \mathrm{~mL}$ set-up, respectively) by absorbance measurements at $271 \mathrm{~nm}$ (Tecan Infinite 424200 Pro, Maennedorf, Switzerland). The polymer concentration was calculated using a PS- $b$-PEO 425 standard curve in the same citric acid solution / N, N-dimethylformamide mixture.

426 The polymer concentration of PBD-b-PEO in the polymersome dispersion was determined by gel427 permeation chromatography. After lyophilization, the polymersomes were dissolved in $N, N-$ 428 dimethylformamide and analyzed using gel-permeation chromatography with the same organic solvent $429(0.5 \mathrm{~mL} / \mathrm{min})$ as mobile phase using the same columns and detector as described above. The area 430 under the curve of the polymer peak was used to calculate the polymer concentration after calibration 431 with a PBD-b-PEO standard curve.

432 The concentration of dye in the fluorescent polymersome dispersion was determined by fluorescence 433 spectroscopy. The dispersion was diluted in $\mathrm{N}, \mathrm{N}$-dimethylformamide (final polymersome dispersion 434 volume fraction $5 \%, v / v)$. The samples were subsequently centrifuged at $5000 \times g$ for 2 min. The 435 fluorescence emission of the supernatant was determined at $510 \mathrm{~nm}$ (excitation wavelength $413 \mathrm{~nm}$ ). 436 The HPTS concentration in the polymersome dispersion was calculated with a HPTS standard curve 437 in the same phosphate buffer/,$N$-dimethylformamide mixture. 


\subsubsection{Quantification of residual dichloromethane}

439 The dichloromethane content was determined using headspace gas chromatography coupled to a

440 flame ionization detector. The samples were mounted by headspace injection (TurboMatrix HS 40, 441 Perkin Elmer, Waltham, MA) and measured by HP6890 (Hewlett Packard, Palo Alto, CA) equipped 442 with a TR-FFAP column (50 $\mathrm{m} \times 0.32 \mathrm{~mm} \times 0.5 \mu \mathrm{m}$, Thermo Fisher Scientific). The samples were 443 heated for $20 \mathrm{~min}$ at $35^{\circ} \mathrm{C}$ and the headspace needle and transfer line were set to 90 and $120^{\circ} \mathrm{C}$, 444 respectively. Samples were injected for $0.04 \mathrm{~min}$ at a total flow of $40.3 \mathrm{~mL} / \mathrm{min}$ using a split flow of $445 \quad 36.5 \mathrm{~mL} / \mathrm{min}$ (split ratio 20:1, pressure $90 \mathrm{kPa}$ ). Helium (Pangas, Dagmarsellen, Switzerland) was 446 selected as the carrier gas. The pressure in the column was constant (90 kPa) and the flow 1.8 $447 \mathrm{~mL} / \mathrm{min}$. The oven temperature was set to $45^{\circ} \mathrm{C}$ for the first 2 min and gradually increased to $130^{\circ} \mathrm{C}$ 448 over the next $6 \mathrm{~min}$. The FID detector was heated to $250^{\circ} \mathrm{C}$ with a hydrogen flow of $55 \mathrm{~mL} / \mathrm{min}$ and an 449 airflow of $300 \mathrm{~mL} / \mathrm{min}$.

\subsubsection{Size and morphology}

451 The diameters of the PS- $b$-PEO (PS fragment size range: 2800 - 4100) and PBD- $b$-PEO 452 polymersomes, liposomes, and microparticles were determined using the Mastersizer2000 laser 453 diffraction particle size analyzer (Malvern Instruments, Malvern, UK). The results are presented as 454 volume distribution (Supplementary Table S1, Supplementary Figure S14). The morphology of the PSb-PEO polymersomes was further analyzed by cryo-scanning electron microscopy (SEM). For cryoSEM, polymersome dispersion in citric acid solution $250 \mathrm{mM}$ at $\mathrm{pH} 2.0$ was loaded on a 6-mm aluminum carrier (sample thickness $200 \mu \mathrm{m}$ ). In a high-pressure freezer (HPM100, Bal-Tec, Vienna, Austria), the sample was vitrified at $-120^{\circ} \mathrm{C}$ and mechanically broken (BAF-060, Bal-Tec). The resulting surface was coated with tungsten, transferred using a VCT100 (Bal-Tec), and imaged by SEM (Leo-1530, Zeiss, Oberkochen, Germany) at $-120^{\circ} \mathrm{C}$ in accordance with the literature. ${ }^{[56]}$

\subsection{Liposome preparation and characterization}

Liposomes composed of (i) 1,2-dipalmitoyl-sn-glycero-3-phosphocholine (DPPC, LIPOID, Ludwigshafen, Germany) or 1,2-distearoyl-sn-glycero-3-phosphocholine (DSPC, LIPOID), (ii) cholesterol (Sigma Aldrich Chemie) and (iii) 1,2-distearoyl-sn-glycero-3-phosphoethanol-amine- $N$ [methoxy(PEO)-2000] (DSPE-PEO, LIPOID) at 54:45:1 mol\% were prepared by the film hydration method. 
467 For the DSPC liposomes, $8.2 \mathrm{mg}$ cholesterol, $20.2 \mathrm{mg}$ DSPC, and $1.3 \mathrm{mg}$ DSPE-PEO were added as 468 chloroform stock solutions to a glass vial. For the DPPC liposomes, $19.7 \mathrm{mg}$ DPPC, $8.7 \mathrm{mg}$ 469 cholesterol, and $1.4 \mathrm{mg}$ DSPE-PEO, were added as chloroform stock solutions to a glass vial. The 470 organic solvent was subsequently removed by nitrogen flow for $2 \mathrm{~h}$ and storage in a vacuum 471 desiccator overnight. The dried film was hydrated with $1 \mathrm{~mL}$ of citric acid solution $250 \mathrm{mM}$ at $\mathrm{pH} 2.0$ at $472300 \mathrm{mOsmol} / \mathrm{kg}$ (lipid concentration $=29.8 \mathrm{mg} / \mathrm{mL}$ ) while heating to $55^{\circ} \mathrm{C}$ and slowly mixing until the 473 lipid film was not visible anymore. The size was determined as laid out in section 4.3.3.

\section{$474 \quad 4.5$ In vitro ammonia uptake studies}

\subsubsection{Ammonia uptake by polymersomes and liposomes}

476 The transmembrane $\mathrm{pH}$-gradient was generated in side-by-side diffusion cells (PermeGear Inc., 477 Hellertown, PA) by dilution in alkaline phosphate buffer (final phosphate concentration $50 \mathrm{mM}, \mathrm{pH} 6.8$, 478 osmolality $300 \mathrm{mOsmol} / \mathrm{kg}$ ) in the absence and presence of the bile salts sodium cholate (SC), sodium 479 deoxycholate (SDC; bile salts for microbiology, Sigma Aldrich Chemie, 1:1 $(\mathrm{m} / \mathrm{m})$ mixture of SC and 480 SDC), and sodium taurocholate (STC, abcr, Zug, Switzerland) at 25/25/0 mM (liposome, PBD-b-PEO,

481 and hypoosmolal PS- $b$-PEO experiments), 12.5/12.5/0 (digestive enzyme experiment), or 30/30/30 $\mathrm{mM}$ (other experiments). In the hypoosmolal conditions, the osmolality was set to $160 \mathrm{mOsmol} / \mathrm{kg}$ by modifying the phosphate concentration to $10 \mathrm{mM}$ and adjusting the sodium chloride concentration accordingly. In the hyperosmolal conditions, the osmolality was set to $620 \mathrm{mOsmol} / \mathrm{kg}$ by adjusting the sodium chloride concentration. In the digestive enzyme experiment, trypsin from porcine pancreas 1 $\mathrm{mg} / \mathrm{mL}$ (approximately $10000 \mathrm{IU} / \mathrm{mL}$, Sigma Aldrich Chemie), a-chymotrypsin from bovine pancreas

487 (Type II) $1 \mathrm{mg} / \mathrm{mL}$ (approximately $40 \mathrm{IU} / \mathrm{mL}$, Sigma Aldrich Chemie), lipase from porcine pancreas (Type II) $3 \mathrm{mg} / \mathrm{mL}$ (approximately $300 \mathrm{IU} / \mathrm{mL}$, Sigma Aldrich Chemie) were added to the bile saltcontaining phosphate buffer. In the high potassium experiment, potassium chloride $200 \mathrm{mM}$ was added to the potassium phosphate buffer $50 \mathrm{mM}$ (final potassium concentration $250 \mathrm{mM}$ ).

The dual-chamber system was separated by a track etch polycarbonate membrane (pore size $=100$ $\mathrm{nm}$, Sterlitech, Kent, WA), physically isolating the vesicles on one side. At $37^{\circ} \mathrm{C}$, the lipid or polymer and the ammonia concentrations within the diffusion cells were $1.75 \mathrm{mg} / \mathrm{mL}$ and $1.5 \mathrm{mM}$, respectively. At the allotted time points, aliquots were taken from the vesicle-free compartment. The ammonia 
495

concentration of the samples was determined by the Berthelot reaction. ${ }^{[13]}$ The ammonia uptake was quantified using equation 1 with the total mass of sequestrant being the total mass of lipid or polymer:

Ammonia uptake $=\frac{\text { Total ammonia }(\mu \mathrm{mol})-\text { free ammonia }(\mu \mathrm{mol})}{\text { Total mass of sequestrant }(\mathrm{g})}$

\subsubsection{Ammonia uptake with microparticles}

To evaluate their ammonia uptake, zeolite (Sigma Aldrich Chemie), poly(methacrylic acid) (PMAA, Lewatit CNP-105, Sigma Aldrich Chemie), mesostructured silica (Sigma Aldrich Chemie), or activated charcoal (Norit, Cabot, Alpharetta, GA) microparticles were incubated at $30 \mathrm{mg} / \mathrm{mL}$ in phosphate buffer $50 \mathrm{mM}\left(\mathrm{pH} 6.8,37^{\circ} \mathrm{C}\right)$ with an ammonia concentration of $1.5 \mathrm{mM}$ under orbital shaking. At the allotted time points, the dispersions were filtered with a $0.2 \mu \mathrm{m}$ syringe filter and the ammonia concentration of the samples was determined by the Berthelot reaction. The ammonia uptake was quantified using equation 1 with the total mass of sequestrant being the total mass of microparticles.

The cation competition experiments with zeolite microparticles $(20 \mathrm{mg} / \mathrm{mL})$ were conducted similarly with a modified buffer (HEPES $100 \mathrm{mM}$ at pH 7.0 supplemented with 50 to $2000 \mathrm{mM}$ sodium, potassium, or calcium) and an incubation time of $30 \mathrm{~min}$ at $37^{\circ} \mathrm{C}$.

\subsection{In vitro stability experiments in dietary fiber hydrogels}

PS- $b$-PEO(2000) polymersomes with PS blocks between 3300 and 4500 were used for the dietary hydrogel experiments.

PS- $b$-PEO polymersomes were incubated in an isotonic phosphate buffer $10 \mathrm{mM}$ at $\mathrm{pH} 6.8$ with different Metamucil ${ }^{\circledR}$ (Metamucil ${ }^{\circledR}$ Regular, Procter \& Gamble Switzerland, Petit-Lancy, Switzerland) concentrations $(5-50 \%, \mathrm{~m} / \mathrm{m})$ for $24 \mathrm{~h}$ at $37^{\circ} \mathrm{C}$. Subsequently, the hydrogel was diluted approx. 1:19 $(\mathrm{m} / \mathrm{v})$ in isotonic phosphate buffer $50 \mathrm{mM}$ at pH 6.8 (final PS- $b$-PEO polymer concentration: $1 \mathrm{mg} / \mathrm{mL}$; final HPTS concentration for the HTPS-containing transmembrane $\mathrm{pH}$ gradient polymersomes and the HTPS/DPX-containing polymersomes: $50 \mu \mathrm{M}$ and $30 \mu \mathrm{M}$, respectively) containing $1.5 \mathrm{mM}$ ammonia (non-fluorescent polymersomes) or no ammonia (fluorescent polymersomes). After $3 \mathrm{~h}$ incubation at $37^{\circ} \mathrm{C}$ under orbital shaking, the dispersions were centrifuged for $5 \mathrm{~min}$ at $4500 \mathrm{xg}$. The samples were filtered with a $0.2 \mu \mathrm{m}$ syringe filter.

For the non-fluorescent polymersomes, the ammonia concentration of the filtered solution was determined using the L-glutamate dehydrogenase (GLDH)-based enzymatic ammonia kit (AM1015, 
523 Randox Laboratories, Crumlin, UK). For the fluorescent transmembrane pH-gradient polymersomes,

524 the fluorescence emission intensities at $510 \mathrm{~nm}$ at an excitation wavelength of $455 \mathrm{~nm}(\mathrm{pH}$-dependent

525 excitation wavelength) and $413 \mathrm{~nm}$ (pH-independent wavelength) were measured (Tecan Infinite 200

526 Pro). The fluorescence emission intensity ratio at these excitation wavelengths was subsequently

527 calculated and compared with the non-pH-gradient control. For the DPX/HPTS-containing

528 polymersomes, the fluorescence emission intensity at $510 \mathrm{~nm}$ at an excitation wavelength of $413 \mathrm{~nm}$

529 (pH-independent wavelength) was measured (Tecan Infinite 200 Pro). To account for incomplete

530 extraction from the hydrogel matrix, the fluorescence intensity of DPX/HPTS-containing polymersomes

531 were corrected with the extraction efficiency of HPTS-only polymersomes (Supplementary Figure

532 S15).

\section{$533 \quad 4.7$ Polymersome ammonia assay}

534 PS-b-PEO(2000) polymersomes with PS blocks between 2800 and 4500 were used for the 535 polymersome-based ammonia assay experiments.

536 The fluorescence excitation spectra of HPTS at $100 \mu \mathrm{M}$ in isotonic citric acid solution $5.5 \mathrm{mM}(\mathrm{pH}$ 2.0-

537 5.7) or isotonic phosphate buffer $50 \mathrm{mM}(\mathrm{pH}$ 6.8-11.0) was determined at a fixed emission wavelength 538 of $510 \mathrm{~nm}$ (Tecan Infinite 200 Pro) at room temperature.

539 The samples, standards, or blank were co-incubated with polymersomes in isotonic phosphate buffer

$54050 \mathrm{mM}$ at pH 7.4 at room temperature for $10 \mathrm{~min}$ (unless stated otherwise). The volume fraction of the

541 sample, standard, or blank was $17 \%$ and $43 \%(\mathrm{v} / \mathrm{v})$ per well with a final HPTS concentration of 16 and

$54240 \mu \mathrm{M}$, respectively. The fluorescence emission at $510 \mathrm{~nm}$ was measured at an isosbestic (413 nm)

543 and at a pH-dependent excitation wavelength $(455 \mathrm{~nm})$ to determine the fluorescence emission ratio

544 (i.e., fluorescence emission at $\mathrm{pH}$-dependent excitation wavelength normalized to the emission at the

545 isosbestic excitation wavelength). The fluorescence emission ratio of the ammonia standards was

546 corrected by subtracting the one of the blank (corrected fluorescence emission ratio). The accuracy

547 was defined as the percentage of the mean of the measurements normalized to the nominal ammonia

548 concentration. The precision was defined as coefficient of variation (i.e., standard deviation normalized

549 to mean). The lower limit of quantification (LOQ) was determined using equation 2 which relates to the

550 current guidelines for bioanalytical method validation of the European Medicine's Agency (EMA,

551 EMEA/CHMP/EWP/192217/2009, legal effective date 2012/02/01) 
$552 L O Q=10 \times \frac{\sigma}{m}$

553 where $\sigma$ stands for the standard deviation of the intercept and $\mathrm{m}$ for the slope of the standard curve.

\section{$554 \quad$ 4.7.1 Selectivity}

555 The ammonia concentration of a $100 \mu \mathrm{M}$ ammonia solution (17\%, v/v) was determined in the presence 556 of a mixture of drugs and metabolites (dopamine (TCl), levofloxacin (Sigma Aldrich Chemie), 557 propranolol (Sigma Aldrich Chemie), glycine (Acros), alanine (Roth, Arlesheim, Switzerland), each at $558500 \mu \mathrm{M})$, or di- $(200 \mu \mathrm{M}$, Sigma Aldrich Chemie) or trimethylamine $(100 \mu \mathrm{M}, \mathrm{TCl})$ (final volume fraction $17 \%(\mathrm{v} / \mathrm{v})$ of the solution containing the potentially interfering substance). The ammonia concentration

560 was quantified as described above by comparison to an ammonia standard curve in isotonic 561 phosphate buffer $50 \mathrm{mM}$ at $\mathrm{pH} 7.4$.

\section{$562 \quad$ 4.7.2 Time dependence}

563 Time dependence of ammonia sensing with HPTS-containing PS- $b$-PEO polymersomes. Normalized 564 fluorescence emission ratio of fluorescent polymersomes were exposed to ammonium chloride 50 or $565200 \mu \mathrm{M}$ in both the low and high standard volume fraction set-ups (17 or $43 \%$ (v/v) with HPTS 566 concentration of 16 and $40 \mu \mathrm{M}$ ) for 5 , 10, or 30 min (separate wells for each time point) before the 567 fluorescence emission intensity was measured as described above. The fluorescence emission ratio at 56810 or 30 min was normalized to the one at $5 \mathrm{~min}$.

\subsubsection{Stability at $4^{\circ} \mathrm{C}$}

570 Fluorescent polymersomes were purified with phosphate buffer $50 \mathrm{mM}$ at $\mathrm{pH} 7.4$ as described above 571 and stored for 5 months at $4^{\circ} \mathrm{C}$ protected from light. The polymersome assay was conducted as 572 described above and the fluorescence emission ratio of a phosphate buffer blank was subtracted 573 (corrected fluorescence emission ratio).

\subsubsection{Phenylalanine sensing}

575 Commercial phenylalanine ammonia lyase from Rhodotorula glutinis (EC number 4.3.1.5, grade I, 576 activity: $0.8-2.0$ units/mg protein ( 1 unit converts $0.001 \mathrm{mmol}$ phenylalanine per $\mathrm{min}$ at $\mathrm{pH} 8.5$ at $57730^{\circ} \mathrm{C}$ ), Sigma Aldrich Chemie), was purified using centrifugal filtration (cut-off 30 kDa, Vivaspin 500 , 578 Sartorius AG, Goettingen, Germany) eight times for 2 min at $15^{\prime} 000 \times \mathrm{g}$ at $4^{\circ} \mathrm{C}$. Phenylalanine 579 ammonia lyase $(0.026 \mathrm{mg} / \mathrm{mL})$ was incubated with different phenylalanine solutions $(0-1.5 \mathrm{mM}$, 
volume fraction $50 \%$ ) in tris(hydroxymethyl)aminomethane $5 \mathrm{mM}$ at $\mathrm{pH} 8.5$ at $300 \mathrm{mOsmol} / \mathrm{kg}$ for 15 $\min$ at $30^{\circ} \mathrm{C}$. The samples were subsequently incubated with fluorescent polymersomes as described above (volume fraction of sample $43 \%$ ) and the fluorescence emission ratio measured as described above.

\subsubsection{Quantification in other body fluids}

\subsubsection{Saliva, semen, urine, sweat}

586 Saliva, semen, urine, sweat (all from healthy human donors, Lee BioSolutions, Maryland Heights, MO) 587 were incubated with fluorescent polymersomes at final sample volume fractions of $0.17 \%$ (semen, 588 urine) or $1.7 \%$ (saliva, sweat) for $10 \mathrm{~min}$ at room temperature (HPTS concentration $16 \mu \mathrm{M}$ ). The 589 concentrations were calculated with an ammonia standard curve in isotonic phosphate buffer at $\mathrm{pH}$ 590 7.4. The samples were volumetrically diluted in isotonic phosphate buffer at pH 7.4 1/100 (semen, 591 urine) or 1/10 (saliva, sweat) and measured with the GLDH assay.

\subsubsection{Intestinal fluid}

593 Caecum fluid from healthy female Sprague Dawley rats (8-10 weeks old) was centrifuged for $10 \mathrm{~min}$ at $59415^{\prime} 000 \times g$ at $4^{\circ} \mathrm{C}$. The supernatant was spiked with ammonium chloride standards in water (final 595 volume fraction of standard 10\%). The spiked caecum samples were incubated with fluorescent 596 polymersomes at a final sample volume fraction of $0.5 \%$ for $10 \mathrm{~min}$ at room temperature. The 597 fluorescence emission ratio was subsequently measured as described above, and the fluorescence 598 emission ratio emission of a phosphate buffer blank was subtracted (corrected fluorescence emission 599 ratio).

\section{4.8. In vivo experiments with BDL rats}

601 The animal experiments adhered to national guidelines and were approved by the local ethics 602 committee of the Centre de Recherche du CHUM (CIPA, Montreal, QC, Canada). Secondary biliary 603 cirrhosis was induced in male Sprague-Dawley rats (ca. 220 g) (Charles River Laboratories, St. 604 Constant, QC, Canada) by surgical bile duct ligation (BDL). In brief, laparotomy was performed and 605 the common bile duct was located, ligated, and resected using a dissection microscope as described 606 previously. ${ }^{[57]}$ 
608 In the first part of the oral study, the laxative effects of poly(ethylene glycol) (3350) (PEG, $1 \mathrm{~g} / \mathrm{kg}, \mathrm{n}=$

6093, Pegalax $^{\circledR}$, Aralez Pharmaceuticals, Mississauga, ON, Canada), sodium picosulfate $(25 \mathrm{mg} / \mathrm{kg}, \mathrm{n}=$

610 19, i.e., same animals used in the next paragraph, Dulcolax ${ }^{\circledR}$ Picosulfate, Sanofi Aventis, Vernier,

611 Switzerland), and the negative control (water, $n=6$ ) were determined. The laxatives were diluted in

612 water and gavaged once daily at 8.30 a.m. ( $5 \mathrm{~mL} / \mathrm{kg})$ in $\mathrm{BDL}$ rats at three weeks after surgery. Fresh

613 stool samples were collected after 8 and $24 \mathrm{~h}$ and dried at $70^{\circ} \mathrm{C}$ overnight. The water loss of the stool

614 samples after drying was quantified gravimetrically.

615 In the second part, the effects of an orally applied polymersome dispersion $(1 \mathrm{~g}$ polymer $/ \mathrm{kg}$ per day,

616 diblock copolymers from Supplementary Table S7, individual polymersome batches were pooled and

617 gavaged as is, i.e., dispersed in citric acid solution $250 \mathrm{mM}$ at $\mathrm{pH}$ 2.0) was assessed in BDL rats

618 supplemented with sodium picosulfate $(25 \mathrm{mg} / \mathrm{kg}$ per day). Three weeks after surgery, blood was

619 sampled from the saphenous vein into heparin-containing tubes (Sandoz Canada, Boucherville, QC,

620 final concentration approx. $20 \mathrm{IU} / \mathrm{mL}$ ) and centrifuged at $1500 \times g$ at $4^{\circ} \mathrm{C}$ for $7 \mathrm{~min}$. The ammonia

621 levels in the heparinized plasma were immediately measured using the PocketChem BA PA-4140 (20

$622 \mu \mathrm{L}$ sample, mode F6; PocketChem BA PA-4140, Arkray, Kyoto, Japan). Two groups with similar mean

623 ammonia levels were created ( $n=18-19$ per group) which received sodium picosulfate (once daily 25

$624 \mathrm{mg} / \mathrm{kg}$ ) and polymersome dispersion in citric acid solution (twice daily $0.5 \mathrm{~g}$ polymer $/ \mathrm{kg}$ ) or citric acid

625 solution alone (twice daily $0.24 \mathrm{~g}$ citric acid $/ \mathrm{kg}$, i.e., corresponding to citric acid dose received by the

626 polymersome group) by gavage twice daily (10.30 a.m. and 5 p.m.) for one week (total gavage

627 volume: $15 \mathrm{~mL} / \mathrm{kg}$ per day). A group of age-matched healthy rats $(\mathrm{n}=6)$ served as control and

628 received citric acid solution (twice daily $0.24 \mathrm{~g} / \mathrm{kg}$ ) by gavage for one week (15 mL/kg per day). At day

629 seven, the second dose of polymersome dispersion or citric acid solution was administered at 1 p.m.

630 and the rats were sacrificed at 3.30 p.m. Arterial blood was collected by cardiac puncture in heparin-

631 containing tubes (final concentration $10 \mathrm{IU} / \mathrm{mL}$ ) and centrifuged at $1500 \times g$ at $4^{\circ} \mathrm{C}$ for 7 min. The

632 ammonia levels in the heparinized plasma were immediately measured with the PocketChem BA as

633 described above. Three and one deaths occurred in the polymersome and the citric acid group,

634 respectively. All deaths occurred right after the gavage procedure.

\section{4.8.2 Quantification of ammonia in rat plasma}

636 The polymersome assay was evaluated in rat plasma. BDL rats at four weeks after surgery and 637 weight-matched healthy male Sprague-Dawley rats were used. Approximately $5 \mathrm{~mL}$ of arterial blood 
638 were collected by cardiac puncture in heparin-containing tubes (final concentration $10 \mathrm{IU} / \mathrm{mL}$ ) and 639 centrifuged at $1500 \times g$ at $4^{\circ} \mathrm{C}$ for $7 \mathrm{~min}$. The samples were frozen and stored at $-80^{\circ} \mathrm{C}$. After thawing 640 on ice, the ammonia concentration was analyzed with the polymersome assay (compared with a 641 standard curve in phosphate buffer at $\mathrm{pH}$ 7.4) as described above using a different plate reader 642 (Tecan Spark $^{\circledR}$ 20M, Tecan), the enzymatic GLDH-based ammonia assay, and the PocketChem BA. 643 Selected biochemical laboratory parameters (alanine transaminase, ALT, aspartate transaminase, 644 AST, albumin, total bilirubin, alkaline phosphatase, AP, gamma-glutamyl transpeptidase, GGT) were 645 analyzed from BDL plasma samples at the CHUM (Montréal, QC, Canada).

\subsection{Commercial ammonia assays}

647 In the GLDH enzymatic ammonia kit, the samples were measured based on the manufacturer's 648 instructions with a modified sample $(20 \mu \mathrm{L})$, reagent buffer $(200 \mu \mathrm{L})$, and the enzyme solution volume $649(2 \mu \mathrm{L})$ in order to adapt the protocol to a 96-well plate set-up. ${ }^{[14,15]}$ In brief, the ammonia-containing 650 solution, blank, or calibrator was added to the reagent buffer (trometamol $150 \mathrm{mM}$ at pH 8.6) in the 651 well and incubated for $5 \mathrm{~min}$ at room temperature. After measuring the baseline absorbance at $340 \mathrm{~nm}$ 652 (Tecan Infinite 200 Pro), the enzyme was added and the absorbance at the same wavelength was 653 measured after 5 min incubation at room temperature. Based on an ammonium chloride standard 654 curve $(25-200 \mu \mathrm{M})$, the lowest concentration with acceptable accuracy (between $80-120 \%$ ) and 655 precision (CV below 20\%) was determined (50 $\mu \mathrm{M})$. The measurements below this value were set as $65625 \mu \mathrm{M}$ in accordance with the literature. ${ }^{[14]}$

657 To measure ammonia levels with the PocketChem BA, $20 \mu \mathrm{L}$ of sample was applied onto the strip 658 (Ammonia Test Kit II, Arkray) and measured in mode F6 according to the manufacturer's instructions. 659 To establish the ammonia standard curve, the ammonia standard from the Randox enzymatic 660 ammonia assay $(298 \mu \mathrm{M})$ was taken and diluted in water. The standards were measured in mode F6 661 according to the manufacturer's instructions. In the TMA measurements with the PocketChem BA, 662 TMA standards in phosphate buffer at pH 8.0 were prepared, applied on the strip, and measured after 6631 min incubation.

664 In the ammonia quantification using the Berthelot reaction, the ammonia-containing sample was 665 added to equivolumetric amounts of alkaline sodium hypochlorite and phenol nitroprusside solution 
666 (both from Sigma Aldrich Chemie). After $25 \mathrm{~min}$ of incubation at room temperature, the absorbance

667 was measured at $636 \mathrm{~nm}$ (Tecan Infinite 200 Pro).

\section{$668 \quad 4.10$ Statistical analysis}

669 The statistical calculations were carried out by SigmaPlot (version 13.0) and Microsoft Excel 2016

670 (determination of $\mathrm{R}^{2}$ ). Three or more groups were compared using one-way ANOVA (Holm-Sidak test)

671 assuming a normal distribution of the data. In ammonia uptake kinetics with side-by-side diffusion

672 cells, the time point at $24 \mathrm{~h}$ was compared between groups with this test. Two groups were compared

673 using an unpaired t-test. A p-value of $<0.05$ was deemed statistically significant. 


\section{$674 \quad$ Acknowledgements}

675 S.M. gratefully acknowledges a doctoral scholarship from the Swiss Chemical Industry (SSCI). We 676 further acknowledge generous funding from the Swiss National Science Foundation (2-77082-16). We 677 further thank Julia Müller, Dr. Valentina Agostoni, Dr. Meriam Kabbaj, Dr. Vincent Forster, Prof. Dr. 678 Davide Brambilla, Dr. Jong-Ah Kim, Nevena Paunovic, Prof. Dr. Georgios Sotiriou, Dr. Anastasia 679 Spyrogianni, Dr. Charlotte Gourmel, and Olha Wuerthinger for their support. Our thanks also go to 680 Prof. Dr. Peter Walde for insightful discussions. Finally, we thank Susanne Freedrich (EPIC) for 681 providing caecum content and scopeM for the assistance in the cryo-SEM experiment.

\section{Declaration of conflict of interest}

$683 \mathrm{JCL}, \mathrm{SM}$, and AS are co-inventors on patent applications related to the technologies described in this 684 manuscript. These patent applications have been licensed to Versantis AG which was co-founded by $685 \mathrm{JCL}$. 
688 [1] E. F. M. Wijdicks, N. Engl. J. Med. 2016, 375, 1660.

689 [2] S. Matoori, J.-C. Leroux, Adv. Drug Deliv. Rev. 2015, 90, 55.

690 [3] H. Vilstrup, P. Amodio, J. Bajaj, J. Cordoba, P. Ferenci, K. D. Mullen, K. Weissenborn, P. Wong, Hepatology 2014, 60, 715.

J. P. Ong, A. Aggarwal, D. Krieger, K. A. Easley, M. T. Karafa, F. Van Lente, A. C. Arroliga, K. D. Mullen, Am. J. Med. 2003, 114, 188.

J. Häberle, N. Boddaert, A. Burlina, A. Chakrapani, M. Dixon, M. Huemer, D. Karall, D. Martinelli, P. S. Crespo, R. Santer, A. Servais, V. Valayannopoulos, M. Lindner, V. Rubio, C. Dionisi-Vici, Orphanet J. Rare Dis. 2012, 7, 32.

G. A. Diaz, L. S. Krivitzky, M. Mokhtarani, W. Rhead, J. Bartley, A. Feigenbaum, N. Longo, W. Berquist, S. A. Berry, R. Gallagher, U. Lichter-Konecki, D. Bartholomew, C. O. Harding, S. Cederbaum, S. E. McCandless, W. Smith, G. Vockley, S. A. Bart, M. S. Korson, D. Kronn, R. Zori, J. L. Merritt, S. C S Nagamani, J. Mauney, C. Lemons, K. Dickinson, T. L. Moors, D. F. Coakley, B. F. Scharschmidt, B. Lee, Hepatology 2013, 57, 2171.

V. R. Patwardhan, Z. G. Jiang, Y. Risech-Neiman, G. Piatkowski, N. H. Afdhal, K. Mukamal, M.

J. M. Vierling, M. Mokhtarani, R. S. Brown, P. Mantry, D. C. Rockey, M. Ghabril, R. Rowell, M. Jurek, D. F. Coakley, B. F. Scharschmidt, Clin. Gastroenterol. Hepatol. 2016, 14, 903.

C. Bachmann, Eur. J. Pediatr. 2003, 162, 410.

[11] I. Seiden-Long, K. Schnabl, W. Skoropadyk, N. Lennon, A. McKeage, Clin. Biochem. 2014, 47,

[12] R. Goggs, S. Serrano, B. Szladovits, I. Keir, R. Ong, D. Hughes, Vet. Clin. Pathol. 2008, 37, 198.

[13] V. Forster, R. D. Signorell, M. Roveri, J.-C. Leroux, Sci. Transl. Med. 2014, 6, 258ra141.

[14] V. Agostoni, S. H. Lee, V. Forster, M. Kabbaj, C. R. Bosoi, M. Tremblay, M. Zadory, C. F. Rose, J.-C. Leroux, Adv. Funct. Mater. 2016, 26, 8382. 
721 [16] E. Moroz, S. Matoori, J.-C. Leroux, Adv. Drug Deliv. Rev. 2016, 101, 108.

722 [17] T. T. Kararli, Biopharm. Drug Dispos. 1995, 16, 351.

723 [18] K. T. Kim, J. J. L. M. Cornelissen, R. J. M. Nolte, J. C. M. van Hest, Adv. Mater. 2009, 21, 2787.

[19] R. S. M. Rikken, H. Engelkamp, R. J. M. Nolte, J. C. Maan, J. C. M. van Hest, D. A. Wilson, P.

[20] J.-F. Le Meins, O. Sandre, S. Lecommandoux, Eur. Phys. J. E. Soft Matter 2011, 34, 1.

[21] H. Bermudez, A. K. Brannan, D. A. Hammer, F. S. Bates, D. E. Discher, Macromolecules 2002, 35, 8203.

D. Richter, R. Zorn, B. Farago, B. Frick, L. J. Fetters, Phys. Rev. Lett. 1992, 68, 71.

[23] T. G. Fox, P. J. Flory, J. Polym. Sci. 1954, 14, 315.

[24] C. R. Bosoi, C. Parent-Robitaille, K. Anderson, M. Tremblay, C. F. Rose, Hepatology 2011, 53, 1995.

[25] R. Schubert, H. Jaroni, J. Schoelmerich, K. H. Schmidt, Digestion 1983, 28, 181.

[26] K. Andrieux, L. Forte, S. Lesieur, M. Paternostre, M. Ollivon, C. Grabielle-Madelmont, Eur. J. Pharm. Biopharm. 2009, 71, 346.

[27] C. J. O'Connor, R. G. Wallace, K. Iwamoto, T. Taguchi, J. Sunamoto, Biochim. Biophys. Acta Biomembr. 1985, 817, 95.

[28] R. N. Rowland, J. F. Woodley, Biochim. Biophys. Acta - Lipids Lipid Metab. 1980, 620, 400.

[29] O. Zumbuehl, H. G. Weder, Biochim. Biophys. Acta - Biomembr. 1981, 640, 252.

M. Kokkona, P. Kallinteri, D. Fatouros, S. G. Antimisiaris, Eur. J. Pharm. Sci. 2000, 9, 245.

[31] V. Pata, F. Ahmed, D. Discher, N. Dan, Langmuir 2004, 20, 3888.

M. A. Jama, H. Yücel, Sep. Sci. Technol. 1989, 24, 1393.

M. R. Weir, G. L. Bakris, D. A. Bushinsky, M. R. Mayo, D. Garza, Y. Stasiv, J. Wittes, H. ChristSchmidt, L. Berman, B. Pitt, N. Engl. J. Med. 2015, 372, 211.

G. D. Zuidema, D. Cullen, R. S. Kowalczyk, E. F. Wolfman, Arch. Surg. 1963, 87, 296.

M. P. de la C. Moreno, M. Oth, S. Deferme, F. Lammert, J. Tack, J. Dressman, P. Augustijns, J. Pharm. Pharmacol. 2006, 58, 1079. Res. 2006, 23, 165. 
Appl. Mater. Interfaces 2016, 8, 17033.

754 [39] L. Zhang, A. Eisenberg, Science 1995, 268, 1728.

755 [40] E. Ruel-Gariépy, G. Leclair, P. Hildgen, A. Gupta, J.-C. Leroux, J. Control. Release 2002, 82, 356373.

757

758

759

760

761

762

763

764

765

766

767

768

769

770

771

772

773

774

775

776

777

778

779

780

781

782

[41] Ž. Pavelić, N. Škalko-Basnet, J. Filipović-Grčić, A. Martinac, I. Jalšenjak, J. Control. Release 2005, 106, 34.

[42] S. Mourtas, S. Fotopoulou, S. Duraj, V. Sfika, C. Tsakiroglou, S. G. Antimisiaris, Colloids Surfaces B Biointerfaces 2007, 55, 212.

[43] R. M. Straubinger, D. Papahadjopoulos, K. Hong, Biochemistry 1990, $29,4929$.

[44] P. Tiefenboeck, J. A. Kim, F. Trunk, T. Eicher, E. Russo, A. Teijeira, C. Halin, J.-C. Leroux, ACS Nano 2017, 11, 7758.

[45] Z. Horak, J. Kolarik, M. Sipek, V. Hynek, F. Vecerka, J. Appl. Polym. Sci. 1998, 69, 2615.

[46] X. Liang, G. Mao, K. Y. S. Ng, J. Colloid Interface Sci. 2004, 278, 53.

[47] M. P. Desai, V. Labhasetwar, E. Walter, R. J. Levy, G. L. Amidon, Pharm. Res. 1997, 14, 1568.

[48] J. Parmentier, M. M. M. Becker, U. Heintz, G. Fricker, Int. J. Pharm. 2011, 405, 210.

[49] S. Hu, M. Niu, F. Hu, Y. Lu, J. Qi, Z. Yin, W. Wu, Int. J. Pharm. 2013, 441, 693.

[50] T. Teerlink, M. W.T. Hennekes, C. Mulder, H. F. H. Brulez, J. Chromatogr. B Biomed. Sci. Appl. 1997, 691, 269.

[51] R. Obeid, H. M. Awwad, Y. Rabagny, S. Graeber, W. Herrmann, J. Geisel, Am. J. Clin. Nutr. 2016, 103, 703.

[52] A. C. Chakrabarti, I. Clark-Lewis, P. R. Harrigan, P. R. Cullis, Biophys. J. 1992, 61, 228.

[53] R. F. Chen, Arch. Biochem. Biophys. 1974, 160, 106.

[54] N. Blau, F. J. van Spronsen, H. L. Levy, Lancet 2010, 376, 1417.

[55] S. Hocine, D. Cui, M.-N. Rager, A. Di Cicco, J.-M. Liu, J. Wdzieczak-Bakala, A. Brûlet, M.-H. Li, Langmuir 2013, 29, 1356.

[56] L. Isa, F. Lucas, R. Wepf, E. Reimhult, Nat. Commun. 2011, 2, 438.

[57] C. R. Bosoi, M. M. Oliveira, R. Ochoa-Sanchez, M. Tremblay, G. A. Ten Have, N. E. Deutz, C. F. Rose, C. Bemeur, Metab. Brain Dis. 2017, 32, 513. 